\title{
Pebble Morphometric Studies of Part of Bida Formation, Northern Bida Basin, North Central Nigeria
}

\author{
${ }^{1}$ Abdullahi M*, ${ }^{2}$ Goro A.I, ${ }^{2}$ Suleiman T.M, ${ }^{2}$ Folorunsho O.W, ${ }^{1}$ Abubakar M, \\ ${ }^{1}$ Broadlink petroleum Limited, Nigeria \\ ${ }^{2}$ Department of Geology \\ Federal university of technology, PMB 65 Minna, Nigeria
}

\begin{abstract}
The Bida formation exposed in Doko locality, Bida town appeared Massive, poorly sorted with localized sedimentary structures. The formation shows three lithofacies: $\mathrm{mf}$, ssf and sf respectively. The formation grades into more matured upward, the pebbles are found within the sf unit as lenses and as scattered pebbles. Vernier caliper was used to measure the Longest, intermediate and shortest axes that are mutually perpendicular for each pebble. These values were used to compute different morphometric parameters as a single variable including MPSI, OPI, FR, ER, $R$ and $C F$. These parameters were also used as dependent variables in bivariate plots to characterize the depositional process. The average values of MPSI, OPI, FR, ER, and CF are: 0.64 , 3.01,0.41, 0.63, 44.5 and 40.73 respectively. The ternary plot of the ratios of the three-axis showed that most samples fall within Bladed(B) field while some other few on Elongate(E) Field, the plot of MPSI versus OPI, FI versus MPSI and $R$ versus ER. Both independent and dependent parameters showed that the Bida formation was deposited by both river and beach processes. Its therefore deduced that the fluvial deposits were later modified by marine activities, possibly during the transgression period.
\end{abstract}

Key Words: Bida formation, Pebbles Morphometry, Fluvial, Marine.

\section{INTRODUCTION}

The sandstone of Bida formation has been described where it is exposed in Doko locality, Bida town. It appeared Massive, poorly sorted with localized sedimentary structures. The formation shows three lithofacies: $\mathrm{mf}$, ssf and sf respectively. The formation grades into more matured upward, the pebbles are found within the sf unit as lenses and as scattered pebbles. Vernier caliper was used to measure the Longest, intermediate and shortest axes that are mutually perpendicular for each pebble. These values were used to compute different morphometric parameters as a single variable including MPSI, OPI, FR, ER, R and CF. These parameters were also used as dependent variables in bivariate plots to characterize the depositional process. The average values of MPSI, OPI, FR, ER, and CF are: $0.64,3.01,0.41,0.63,44.5$ and 40.73 respectively. The ternary plot of the ratios of the three-axis showed that most samples fall within Bladed(B) field while some other few on Elongate(E) Field, the plot of MPSI versus OPI, FI versus MPSI and $\mathrm{R}$ versus ER. Both independent and dependent parameters showed that the Bida formation was deposited by both river and beach processes. Its therefore deduced that the fluvial deposits were later modified by marine activities, possibly during transgression period. interpreted by different authors notably among them are [1-4]. Part of the sandstone include the pebbly sandstone of the Bida formation [1]. Although the broad study of the deposits has been interpreted by these authors the pebble morphometric analysis of the pebbles contained in the pebbly sandstone has not been done. This aspect involves the measurement of three mutually perpendicular axis namely, Longest, Intermediate and shortest axis of individual pebble, and has been used by several workers to infer the depositional condition as well as environment of deposition e.g[5-11]. Recent works in Nigeria include: [12][13]14] etc.

The purpose of this study is to analyse the pebbles of the pebbly sandstone in order to infer the condition and environment of deposition of the pebbly sandstone unit of bida formation exposed in mesa near Doko village, the type locality of the doko member of Bida sandstone, Bida basin Nigeria.

Pebble morphometry studies were employed in the study of Depositional environment of the Bida formation exposed around Doko locality, Bida North central Nigeria. The formation under study is part of the northern Nupe basin which composed predominantly of massive arkosic sandstone with lenses of pebbles at the lower stratigraphic level. This arkosic unit appeared to grade into arenaceous upward. The importance of pebbles morphometry has been understood since early days by many workers 
in interpreting the paleoenvironment of deposition and provenance study. On a broader sense pebble morphometry consider Form, sphericity, roundness and surface features of the grains [15]. Form described the relationship between the three axes of particles (Longest, intermediate and shortest axes), Sphericity is the measure of how equal these axes are, such that the grains with almost same grain axes has high sphericity than the one with different axial length. The main control of sphericity is pebble lithology [15][16]. [15] found that Quartz and Chert sphericity increase downstream while limestone remains constant. Roundness refers to a degree of sharpness of the corners and edges of a grain. Roundness measurement and its implications is known by many, example [5-11]. The pebbles parameters such as roundness chart of [11], Flatness and elongation ratio of [17], Maximum Projection Sphericity Index(MPSI) and Form names of [18], etc. was used as independent variables to interpret the environment of deposition exposed in mesas in the study area. These parameters had also been used as dependent variables in bivariate plots such as MPSI vs OP, roundness Vs elongation ratio, to characterize the depositional environment and ternary plot of [18].

\section{LOCATION AND REGIONAL GEOLOGICAL SETTING}

The Bida basin is one of the inland sedimentary basins of Nigeria (figure 1)). The basin is geographically divided in to Northern, central and Southern sub-basins (Figure 1). It's a NW -SE trending intracratonic sedimentary fill extending from Kontagora in Niger State to areas beyond Lokoja in the South, the basin is bounded by a basement complex in the North east and South west and it merges with Anambra and Sokoto basin. The basin comprises of post orogenic molase facies and few thin unfolded marine sediment [4]. The Bida formation has been characterized with a generally massive and flat bedded arkoses coarse to medium grain sandstone with breccia With a thickness of about 4400 and 4800m within two depocenters based on airborne magnetometry [19] [3]. The pebbles in the study area occur as lenses within the massively bedded sandstone.

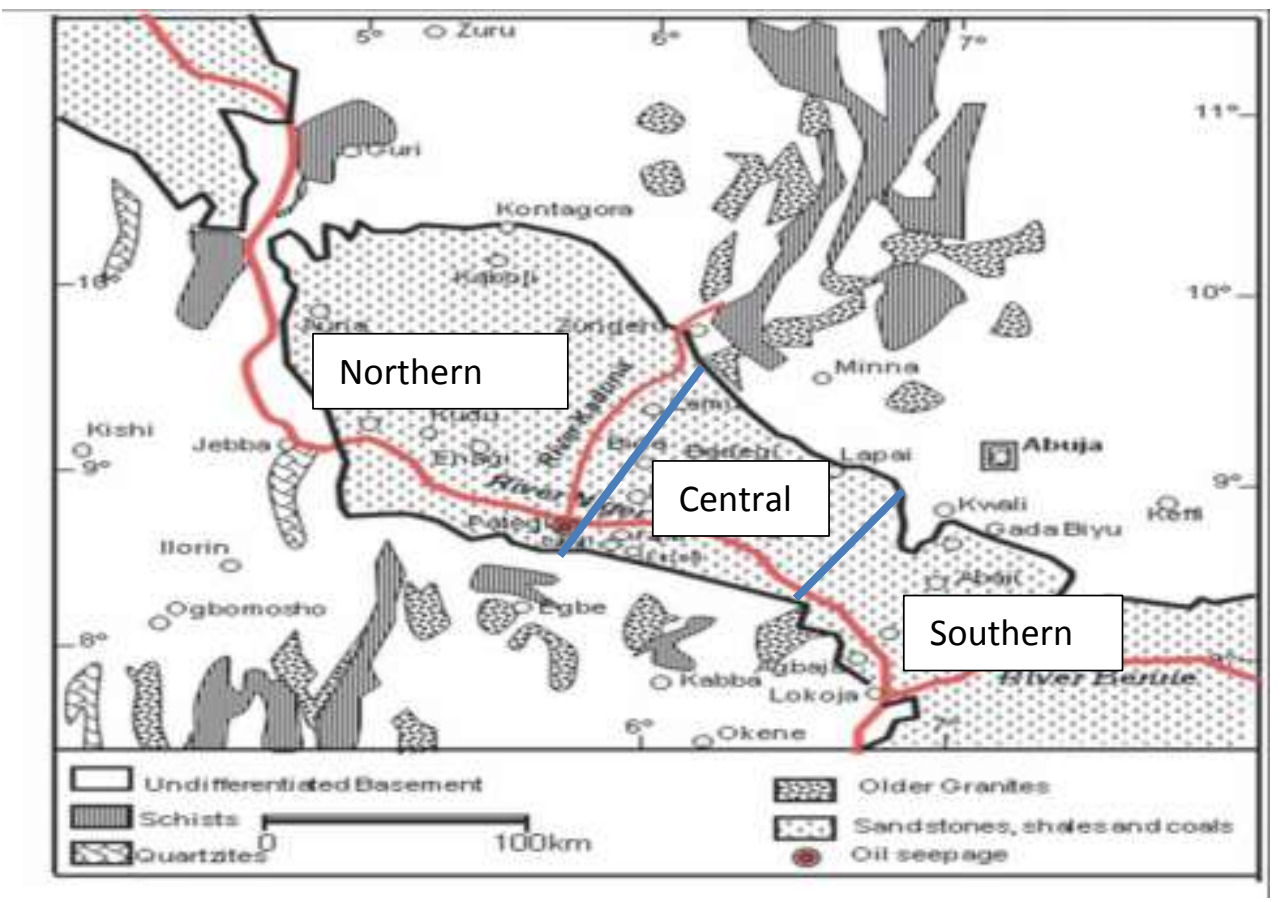

Figure 1: Location of Northern, Central and Southern Bida Basin (Modified After Obaje, 2011)

\section{MATERIALS AND METHOD}

Sedimentological graphic logs detailing the textures and structures of part of the Pebbly sandstone of Bida Formation exposed around Doko locality was undertaken. About $15 \mathrm{~m}$ of section was logged in a Mesa located about $700 \mathrm{~m}$ SW of Doko village. A total of 200 unbroken pebbles of almost the same size were picked in 20 different locations on the outcrop. Standard sampling method was followed [20][12]. The pebble samples were taken in sets, with a total of 20 sets. Each set had 10 pebbles that were measured and averaged for tabulation. While taking the samples, special caution was taken to avoid abnormal pebbles.

The measurement followed the method proposed by [21] where vernier caliper was used to measure the three mutually perpendicular axes of the individual pebble. [18] introduced the terminologies: Longest (L), intermediate (I) and shortest(S) to represent the three axes. This result was tabulated and used to calculate the various morphometric parameters including: maximum 
projection sphericity index (MPSI), Flatness Ratio(FR), Elongation Ratio (ER), Oblate-prolate index (OPI). These parameters were used independently to interpret the paleoenvironment of deposition and also as dependent variables in binary plots. Geological interpretations were achieved using plot such as MPSI vs OPI [22]; Flatness index vs MPSI [7], and Roundness vs elongation of [11]. Estimation chart suggested by [23] was used to interpret the roundness of the pebbles. The form of the pebbles was determined using the ternary plots of [18].

\section{RESULTS AND DISCUSSION}

\subsection{Outcrop description}

About 20m interval belonging to the Bida Formation was studied. Three facies were recognized including sandstone facies, siltstone facies and mudstone facies. The sandstone facies predominate covering more than $70 \%$ of the interval. It consists of medium to very coarse, generally poorly sorted, pebbly, arkosic sandstone. The mudstone facies unconformably underlies the siltstone facies. It displays grey and purple colours with bioturbated intensities generally high the base of the interval not identified, it has a thickness ranging from 1 to about $3 \mathrm{~m}$ in section. The siltstone facies occur as thin units about $5 \mathrm{~m}$ thick overlying the mudstone facies. It displays grey to brown colour which is massive and poorly sorted. The sandstone bed range from less than $1 \mathrm{~m}$ to more than $10 \mathrm{~m}$ interval, they are generally massive with localized trough cross bedding. The pebbles range from small to medium pebbles and may occur either scattered within beds or as discontinuous lenses within beds(figure 2). The sandstones are generally bioturbated and colour mottled displaying reddish brown, yellow, orange and brown colours. The beds also show fining-up grain size with thin lag deposit occupying the base of the units.

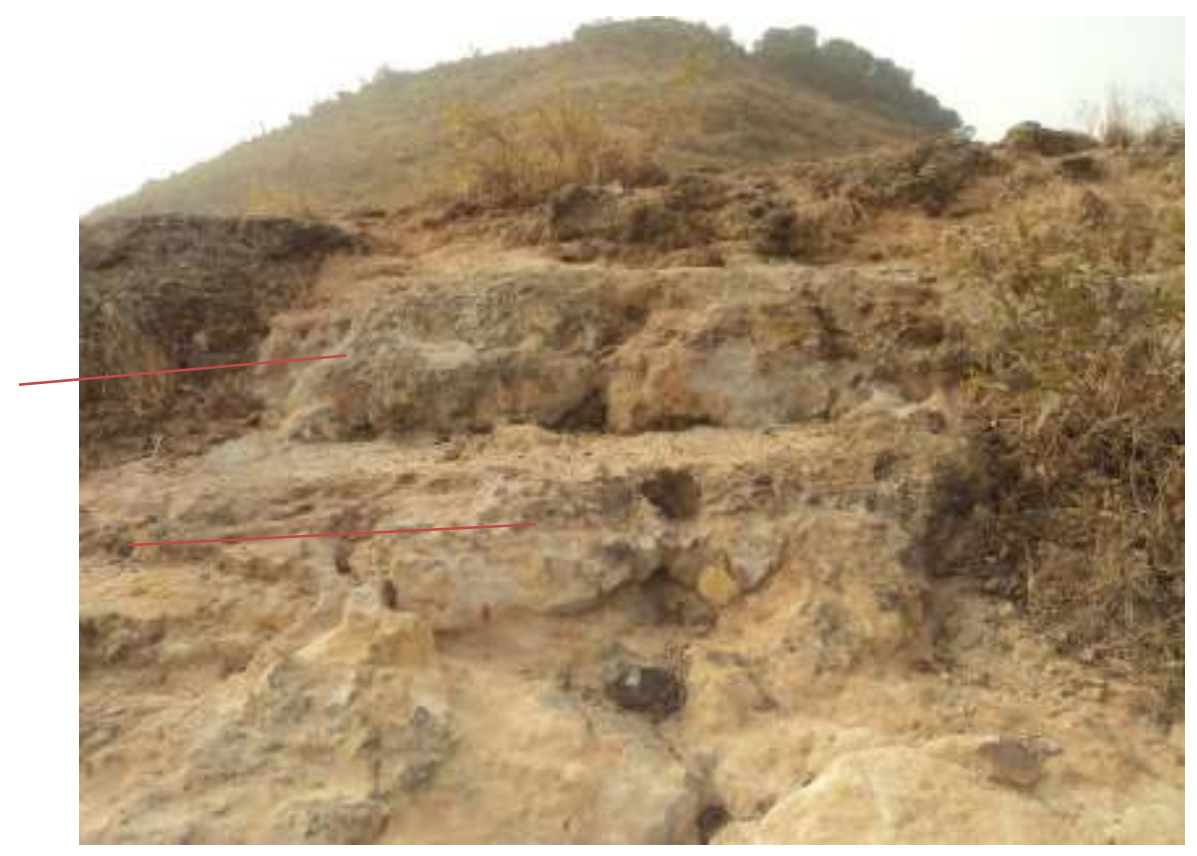

Figure 2: Localized Lenses of pebbles within the sandstone facies (red lines)

In general the formation consist of poorly sorted arkosic Unit and relatively more Arenaceous unit that is fairly sorted. In some places the Pebbles unit exist as a matrix with muddy ground mass (Figure 3) while in other places they appeared as a lenses within the sf (Figure 2). The most common sedimentary structures observed include cross bedding and Bioturbation. Palaeocurrent direction shows that the sediments were sourced from the Southern part of the study area possibly from the surrounding Basement complex. Foliated pebbles (Figure 3) in the study area may be a good evidence that Zungeru Shist belt is the provenance. 


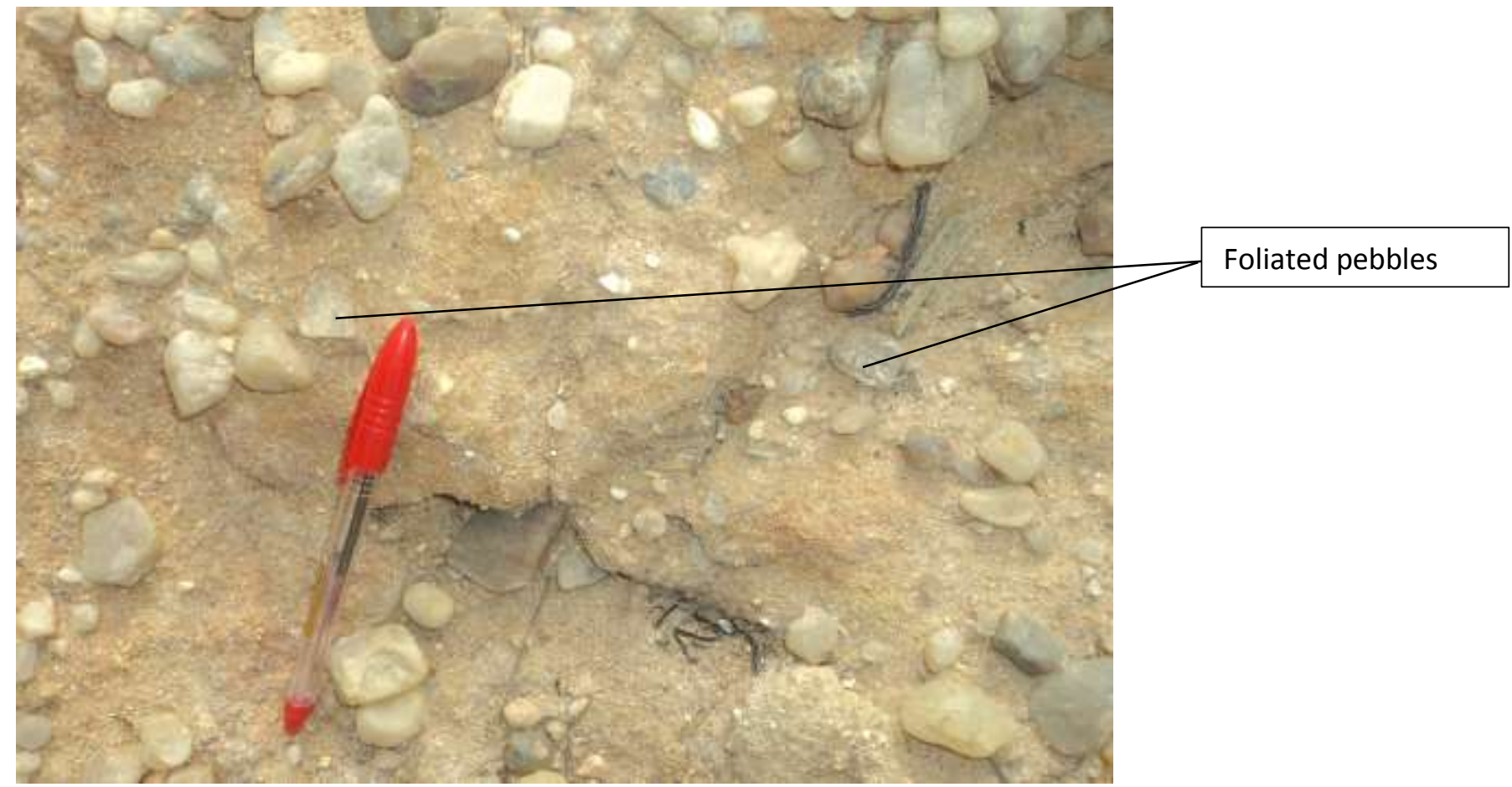

Figure 3: foliated pebbles indicating metamorphic provenance.

\subsection{Pebble Morphometry}

The average values of the parameters obtained for this study are presented in Table 1. Each sample set represents an average of 10 pebbles. From the table, the elongation ratio ranges between (0.36-0.35) with an average of 0.41 , elongation ratio (E.R) ranges from (0.58-0.67) with average of 0.63, coefficient of flatness (CF) ranges from (36.81-44.75) with average of 40.73, maximum projection sphericity Index (MPSI) ranges between (0.59-0.67) with average of 0.64, Oblate Prolate Index (OPI) ranges between(0.63-5.09) with an average of 3.01 and roundness ranges from (40-56\%) with the average of $45.5 \%$.

Table 1. summary of various morphometric parameters

\begin{tabular}{lllllllllll}
\hline S/NO & L & I & S & FR & ER & CF & MPSI & OPI & R & F/N \\
\hline S1 & 3.58 & 2.27 & 1.38 & 0.39 & 0.64 & 39.15 & 0.62 & 2.57 & 52 & B \\
S2 & 3.71 & 2.18 & 1.46 & 0.39 & 0.59 & 39.37 & 0.64 & 4.63 & 44 & B \\
S3 & 3.71 & 2.18 & 1.44 & 0.39 & 0.60 & 39.43 & 0.64 & 4.35 & 42 & B \\
S4 & 3.82 & 2.33 & 1.4 & 0.37 & 0.61 & 36.81 & 0.61 & 3.15 & 50 & B \\
S5 & 3.41 & 2.21 & 1.35 & 0.40 & 0.65 & 39.68 & 0.62 & 2.01 & 46 & B \\
S6 & 3.15 & 2.08 & 1.14 & 0.36 & 0.67 & 36.38 & 0.59 & 0.63 & 44 & B \\
S7 & 3.03 & 2.01 & 1.28 & 0.42 & 0.67 & 42.12 & 0.65 & 1.59 & 44 & B \\
S8 & 3.16 & 2.08 & 1.4 & 0.45 & 0.66 & 44.75 & 0.67 & 2.55 & 42 & B \\
S9 & 3.49 & 2.09 & 1.31 & 0.38 & 0.60 & 37.63 & 0.62 & 3.77 & 40 & B \\
S10 & 3.31 & 2.13 & 1.33 & 0.40 & 0.65 & 40.19 & 0.63 & 2.33 & 46 & B \\
S11 & 3.15 & 2.11 & 1.33 & 0.43 & 0.67 & 42.69 & 0.65 & 1.67 & 46 & E \\
S12 & 3.13 & 1.97 & 1.33 & 0.43 & 0.64 & 42.59 & 0.66 & 3.24 & 44 & B \\
S13 & 3.44 & 2.03 & 1.33 & 0.39 & 0.59 & 38.86 & 0.63 & 4.43 & 56 & E \\
S14 & 3.2 & 2.08 & 1.33 & 0.42 & 0.65 & 41.87 & 0.65 & 2.32 & 44 & B \\
S15 & 3.15 & 2.03 & 1.39 & 0.44 & 0.65 & 44.03 & 0.67 & 3.01 & 42 & B \\
S16 & 3.22 & 2.12 & 1.26 & 0.39 & 0.66 & 39.26 & 0.61 & 1.49 & 46 & B \\
S17 & 3.31 & 1.96 & 1.31 & 0.40 & 0.60 & 40.04 & 0.65 & 4.49 & 40 & E \\
S18 & 3.14 & 2.07 & 1.47 & 0.47 & 0.66 & 46.97 & 0.69 & 2.99 & 48 & E \\
S19 & 3.23 & 1.87 & 1.32 & 0.41 & 0.58 & 40.93 & 0.67 & 5.09 & 44 & B \\
S20 & 3.17 & 1.96 & 1.31 & 0.42 & 0.62 & 41.75 & 0.65 & 3.78 & 50 & E \\
Mean & $\mathbf{3 . 3 3}$ & $\mathbf{2 . 0 9}$ & $\mathbf{1 . 3 4}$ & $\mathbf{0 . 4 1}$ & $\mathbf{0 . 6 3}$ & $\mathbf{4 0 . 7 3}$ & $\mathbf{0 . 6 4}$ & $\mathbf{3 . 0 1}$ & $\mathbf{4 5 . 5}$ & B \\
\hline
\end{tabular}


The parameters derived from grain shape are very important tools in understanding the transport history and depositional environments of the sediments. [18] introduced the word "form" to describe pebble's shape (figure). They used the three axial ratios on a triangular plot and came up with ten form classes (Figure 4). [22] noticed that this form classes can be related to a particular depositional environment. They found that Compact(C), Compact Bladed (CB), Compact Elongate (CE) and elongate are characterized as fluvial deposits. While Platy (P), Bladed, Very Bladed (VB) and Very Platy (VP) are indicative of Beach environment. For Bida formation, the pebble sets fall on the field of Bladed and Elongate. This is indicating that the bida formation was deposited by Fluvial processes which was largely modified by marine activities as found by [12]in a southern part of the study area.

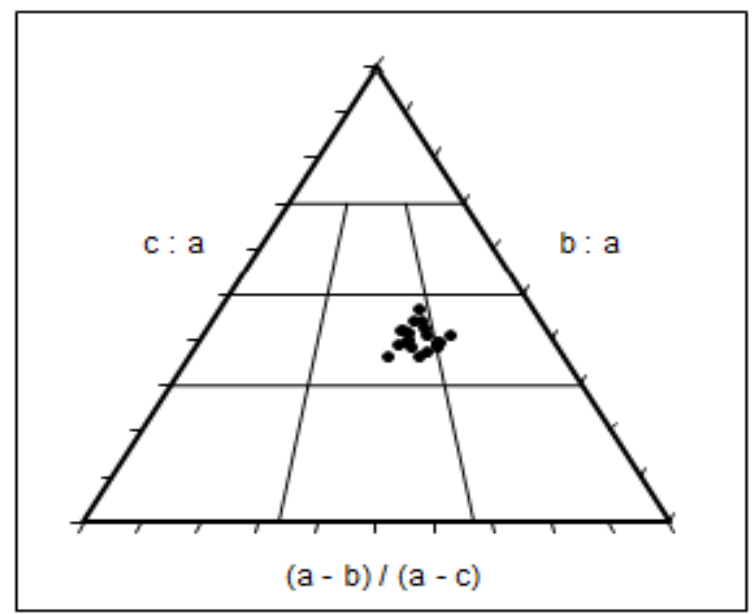

\begin{tabular}{|c|c|c|}
\hline \multicolumn{3}{|c|}{ Sneed \& Folk classes } \\
\hline & Count & Percent \\
\hline Compact & 0 & 0.00 \\
\hline Compact-Platy & 0 & 0.00 \\
\hline Compact-Bladed & 0 & 0.00 \\
\hline Compact-Elongate & 0 & 0.00 \\
\hline Platy & 0 & 0.00 \\
\hline Bladed & 15 & 75.00 \\
\hline Elongate & 5 & 25.00 \\
\hline Very-Platy & 0 & 0.00 \\
\hline Very-Bladed & 0 & 0.00 \\
\hline Very-Elongate & 0 & 0.00 \\
\hline
\end{tabular}

\section{Figure 4: Sneed and Folk triangular plot for the samples. (note: a,b,c stand for shortest, intermediate and longest axis respectively).}

[24][7][18] and [16] described the importance of sphericity of pebbles in the interpretation of depositional environment. [18] was the first to use the name Maximum projection Sphericity to describe how close pebble grain can be approximate to a sphere. In this study [18] sphericity was adopted over [25] because it didn't neglect the effect of hydraulic action hence, obeying stokes law. [22] and [26] suggested a MPSI of less than 0.65 to be of Beach process while that above 0.65 signifies river process. For Bida formation the MPSI ranges between 0.59-0.67 which indicate that the bida formation was deposited by both river and beach depositional processes. the roundness indices is a tool in understanding the transportation history, even though its reliability is questionable because the roundness of sediments depend on the composition of the parents rock, transporting medium and the surface area of the materials. Some pebble grains fracture on transport rather than rounding, for example chert fracture easily during transport. While quartz becomes more rounded but at slow rate [15]. [22] in the Tahiti beaches found that the average roundness of $38 \%$ indicate fluvial pebbles while beach pebbles averaged $52 \%$. For Bida formation the average roundness of twenty sets is $45.5 \%$ which indicate both beaches and river influence. The mean Oblate-Prolate Index (OPI) of river is assumed to exceed -1.5 while that of beach is less than -1.5 . for Bida formation the row data shows the OPI range from (-9.75-14.4) with the average sets of 3.03 , still indicating both river and beach pebbles 

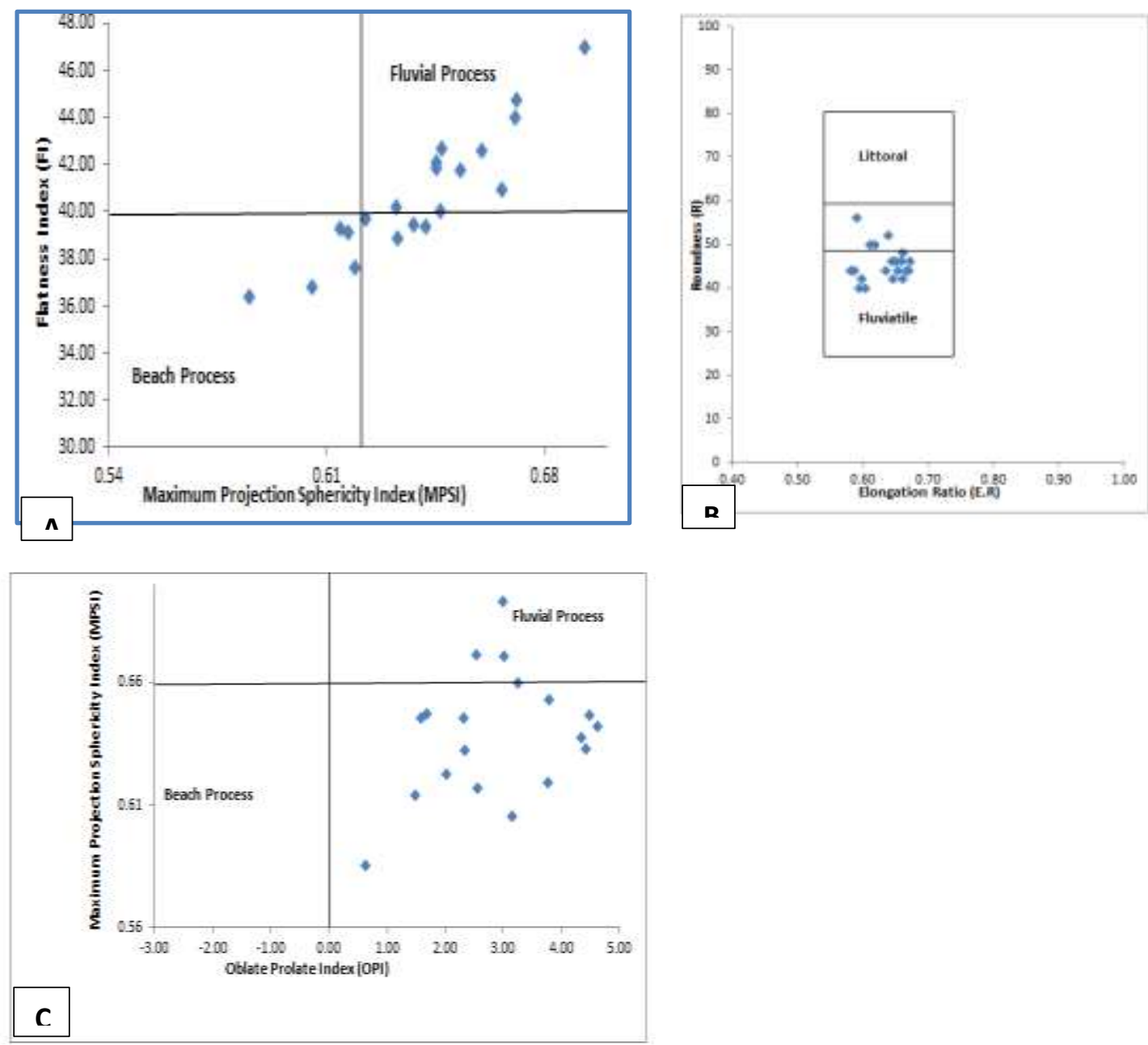

Figure 5: Plot of FI against MPSI by Folk, 1955(A), R against ER by Sames 1966 (B)and MPSI against OPI Dopkins and Folk 1970(C).

Some indices were used dependently to characterize the depositional processes and the environment. [11],[18] and [26] proposed binary plots of Roundness (R) against Elongation ratio (ER), MPSI against OPI and Flatness Index (FI) against MPSI to characterize the depositional processes and environment of the pebbles as to whether Fluvial or Beach. For the Bida formation the plot of MPSI against OPI (Figure5) shows that the pebbles sets fall within the river process field, plot of FI against MPSI (Figure6) shows that most samples fall within Fluvial field while few samples fall under beach field and the plot of Roundness against Elongation ratio (Figure7) shows that, most samples fall within Fluviatile Field while some fall in between Fluviatile and Littoral setting. In general, it is obvious that the Bida formation were deposited by river processes which is later modified by marine processes.

\section{CONCLUSION}

In conclusion the interval studied composed of mudstone facies (mf) that's poorly sorted at lower stratigraphic level, overlying the $\mathrm{mf}$ is a siltstone facies(ssf) and a pebbles supported Sandstone facies(sf), where they appeared as scattered pebbles and as lenses. Generally, the interval indicates increase in maturity upward. The morphometric parameters indicate that the bida formations were deposited by river which is later modified by marginal marine processes, possibly during marine transgression. The presence of ophimorpha burrows also support influence of marine. 


\section{REFERENCES}

1. Adeleye DR, (1974). Sedimentology of the fluvial Bida Sandstones (Cretaceous) Nigeria. Sedimentary Geology 12:1-24.

2. Adeleye D. R. Dessauvagie, T. F. J, 1972 ., stratigraphy of Niger embayment near Bida, Nigeria. African Geol., pp 181 $-186$.

3. Goro A.I., Salihu H.D. , Jibrin B.W. , Waziri N.M. , Idris-Nda A.(2014):Characterization of a Massive Sandstone Interval: Example From Doko Member of Bida Formation, Northern Bida Basin, Nigeria: Universal Journal of geoscience. Vol2(2). pp 53-61.

4. OBAJE, N.G, MOUMOUNI A, GOKI. N.G and CHAANDA. M. S(2011):Stratigraphy, Paleogeography and Hydrocarbon Resource Potentials of the Bida Basin in North- Central Nigeria Journal of Mining and Geology Vol. 47(2), pp. $97-114$

5. Blenk, M., (1960): Ein Beitrag zur morphometrischen Schotteranalyse, •Zeitschrift ftr Geomorphologie, 4, $202-242$.

6. Cailleux, A.(1945): Distinctions des galets marins et fluviatiles, Socigt5ggologique de France, ser. 5(15), 375-404.

7. Folk R.L.(1955): Student operator error in determination of roundness, sphericity and. grain size', journal of Sedimentary Petrology, 25(4), 297-301.

8. Kaiser, K., (1956): Geologische Untersuchungen uber. die Hauptterrasse in der Niederrheinischen Bucht, Sonderver3ffentlichungen des Geologischen Institutes der Universitat AEln 1,(Köln).

9. Kuenen, Ph.H., (1956): Experimental abrasion of pebbles. Rolling by current, Journal of Geology, 64, 336-368.

10. Powers M. (1953): A new roundness scale for sedimentary particles. Journal of Sedimentary Petrology.;23:117-119.

11. Sames, C.W, (1966). Morphometric data of some recent pebble associations and their application to ancient deposits. J. Sedimentary Petrol., 36: 126-142.

12. Salihu, H. D., Goro, A. I., Akande, W. G. and Abdulfatai, I. A. (2017) Pebble Morphometric Analysis and Depositional Environment of the Basal Conglomerates of Bida Sandstone Exposed around Zungeru, NW Nigeria. Book of Proceedings, FUTMINA1st School of Physical Sciences Biennial International conference (SPSBIC), Minna May 4-5, pp 797-808.

13. Okon EE., 2015 Sedimentologic characteristics and provenance studies of AWI formation, Calabar Flank, SE Nigeria. Journal of Mining and Geology.;51(2):121-138.

14. Okon EE, Okah A, and Romeo AO.,2018: Morphometric Studies of Pebbles from Ewen Area, Calabar Flank, Southeastern Nigeria: Implications for Paleoenvironmental Reconstruction. Physical Science International Journal 17(4): $1-12$.

15. Folk R L(1980): Petrology of Sedimentary Rocks: Hemphill Publishing Co. Austin, TX;

16. Wadell, H., 1934: Shape determinations of large sedimental rock fragments, Pan American Geology, 61, 187-220.

17. Luttig, G., 1962. The shape of pebbles in the continental, fluviatile and marine facies. Int. Assoc.Scientific Hydrology Pub., 59: 235-258.

18. Sneed, E.D. and R.L. Folk,(1958). Pebbles in the lower Colorado River, Texas: a study in particle morphogenesis. J. Geol., 66: 114-150.

19. Obi D. A., Ilozobhie A. J. and Abua J. U.(2015): Interpretation of aeromagnetic data over the Bida Basin, North Central, Nigeria. Pelagia Research Library Advances in Applied Science Research, 2015, 6(3): 50-63

20. Odumodu CF, Ephraim BE. (2007): Pebble morphology as as indicator of the depositional environment of the Ajali Sandstone. Natural and Applied Science Journal.;8(2):132-143

21. Krumbein WC. (1941): Measurement and geological significance of shape and roundness of sedimentary particles. Journal of Sedimentary Petrology.;11(2):64-72.

22. Dobkins, J.E. and R.L. Folk, 1970. Shape development on Tahiti-Nui. J. Sedimentary Petrol., 40: 1167-1203

23. Krumbein, W.C., and Sloss, L.L (1956): Stratigraphy and Sedimentation. Freeman and Company, san Francisco CA

24. Folk, R.L, 1984: Petrology of sedimentary rocks. Hemphil Publishing Company, Austin Texas, 182.

25. Wadell H. (1932): Volume, shape, roundness of rock particles: Journal of Geology.; 40:443-451.

26. Stratten T.(1974): Notes on the application of shape parameters to differentiate between beach and river deposits in southern Africa. Transactions of the Geological Society of South Africa.;77:59-64. 